\title{
Endoscopic ultrasound-guided choledochoduodenostomy with a lumen-apposing metal stent through an uncovered metal duodenal stent $\square$
}

다(1)웅

Adrien Sportes, Gheoghe Airinei, Ralph Kamel, Jean Jacques Raynaud, Robert Benamouzig

\author{
Authors \\ Institution \\ Hopital Avicenne, Department of Gastroenterology, \\ Bobigny, France \\ submitted 28.3.2018 \\ accepted after revision 30.5.2018 \\ Bibliography \\ DOI https://doi.org/10.1055/a-0735-9254 | \\ Endoscopy International Open 2018; 06: E1395-E1397 \\ (c) Georg Thieme Verlag KG Stuttgart · New York \\ ISSN 2364-3722 \\ Corresponding author \\ Adrien Sportes, MD, Gastroenterology Unit, Hopital \\ Avicenne (AP-HP), 125 Rue de Stalingrad, 93000 Bobigny, \\ France \\ Fax: +0148955338 \\ adrien.sportes@free.fr
}

\section{ABSTRACT}

Background and study aims Endoscopic retrograde cholangiopancreatography (ERCP) in patients with a preexisting duodenal stent is particularly challenging and has a low success rate. Endoscopic ultrasound (EUS)-guided biliary drainage (EUS-BD) has been increasingly used as an alternative to percutaneous transhepatic biliary drainage after failed ERCP. EUS-guided choledochoduodenostomy (EUSCD) and EUS-guided hepaticogastrostomy (EUS-HGS) have been reported to have similar efficacity. Recently, a novel dedicated fully-covered lumen-apposing metal stent (LAMS) has been developed for EUS-CD (Hot AXIOS; Boston Scientific, Massachusetts, United States). It seems that this new device decreases the morbidity of EUS-CD. We present a case in which EUS-CD with LAMS through an uncovered metal duodenal stent was used successfully.

\section{Introduction}

Endoscopic retrograde cholangiopancreatography (ERCP) in patients with a preexisting duodenal stent is particularly challenging and with low success rate [1]. Recently, a novel, dedicated fully-covered lumen-apposing metal stent (LAMS) has been developed for endoscopic ultrasound (EUS)-guided choledochoduodenostomy (EUS-CD) (Hot AXIOS; Boston Scientific, Massachusetts, United States). We present the case of a successful EUS-CD with LAMS through an uncovered metal duodenal stent.

\section{Case report}

A 56-year-old man with recent abdominal pain and postprandial vomiting underwent a computed tomography (CT) scan, which showed an enlarged tumor of the pancreatic head with duodenal obstruction. Endoscopic ultrasound fine-needle aspiration (EUS-FNA) confirmed the diagnosis of pancreatic adenocarcinoma. At that time, no dilatation of the main bile duct was seen, the liver function test was normal, and no biliary stent was inserted. For a complete duodenal obstruction, an uncovered metal stent duodenal stent was placed.

Two months later, the patient presented with abdominal pain and jaundice. Laboratory tests showed elevated liver function test results: ALT $229 \mathrm{U} / \mathrm{L}(5-45 \mathrm{U} / \mathrm{L})$, AST $181 \mathrm{U} / \mathrm{L}(5-35 \mathrm{U} / \mathrm{L})$, PAL 540U/L (30-110U/L), YGT 6329U/L (7-50U/L), Bilirubin $268 \mu \mathrm{mol} / \mathrm{L}(0-20.5 \mu \mathrm{mol} / \mathrm{L})$. A computed tomography scan revealed biliary tree dilatation with extrinsic pancreatic compression ( $\triangleright$ Fig. 1).

First, ERCP failed to achieve biliary drainage because of an inability to cannulate the papilla due to tumor infiltration. Endoscopic ultrasound-guided hepaticogastrostomy (EUSHCS) was not attempted because the left intrahepatic bile ducts were minimally dilated $(3 \mathrm{~mm})$. However, the common bile duct (CBD) was largely dilated $(20 \mathrm{~mm})$. A Hot AXIOS device with a stent of $8 \times 6 \mathrm{~mm}$ was advanced through the uncovered metal stent. Pure cut electrocautery current was then applied, allowing the device to reach the CBD. Next, the distal flange was opened ( $\triangleright$ Fig.2) and retracted towards the EUS transducer, and once a biliary and bulbar tissue apposition had been noted, the proximal flange was released ( $>$ Fig.3). Good 


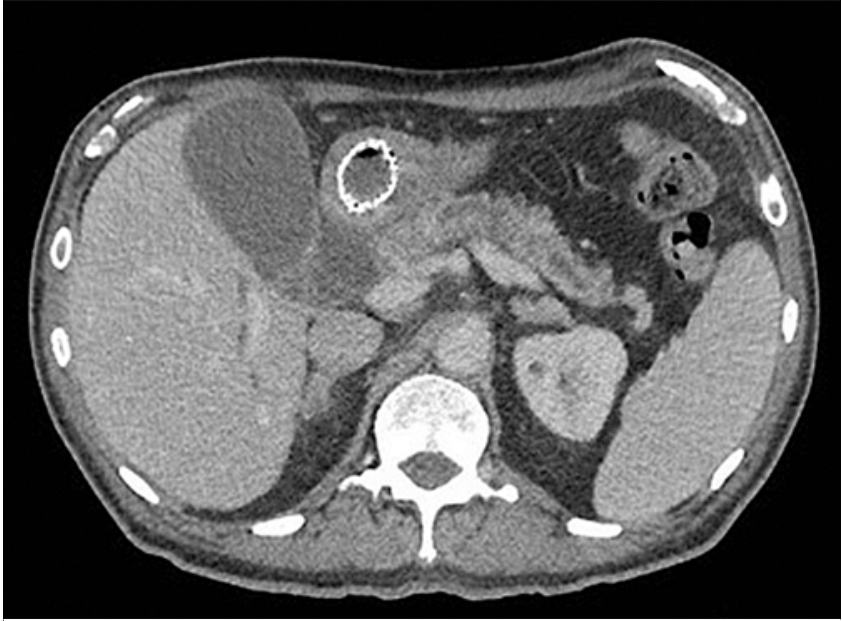

- Fig. 1 Computed tomography scan before endoscopic ultrasound-guided choledochoduodenostomy showed biliary tree dilatation with the duodenal stent in place.

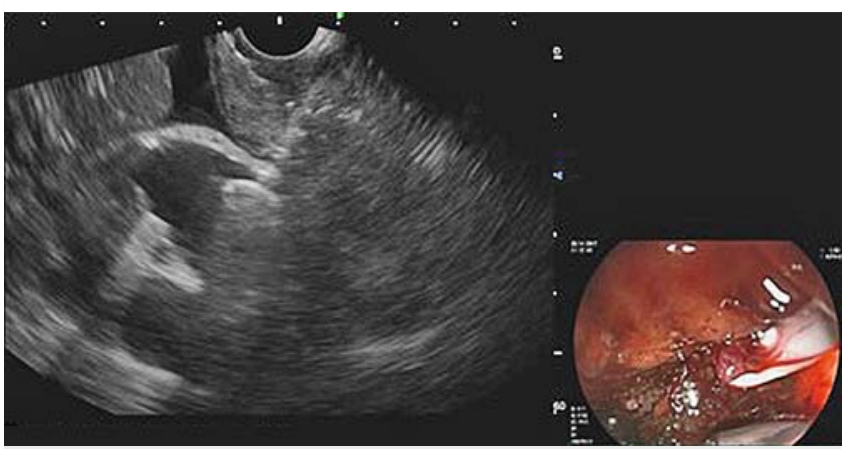

- Fig. 2 Endoscopic ultrasound-guided choledochoduodenostomy with the Hot AXIOS stent and deployment of the distal flange.

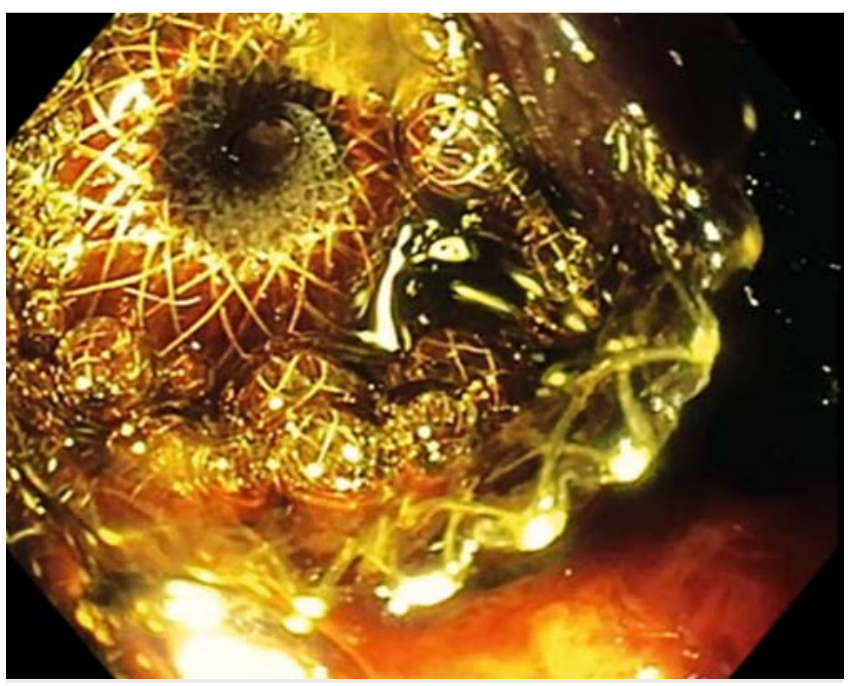

- Fig. 3 Endoscopic view of the lumen-apposing metal stent in the duodenum.

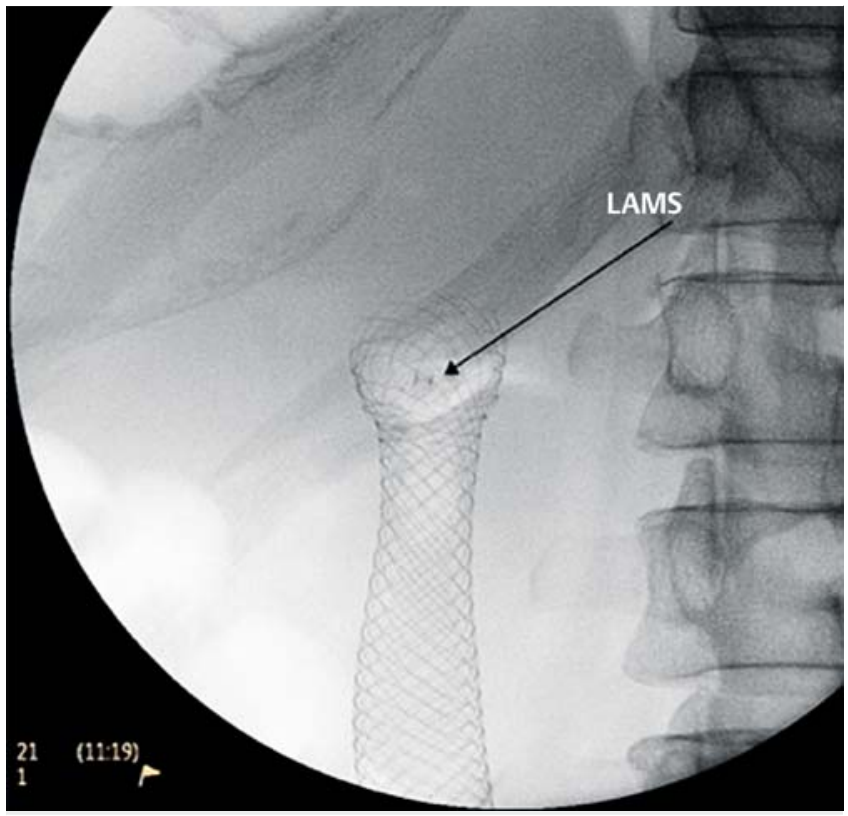

Fig. 4 Radioscopic view of the lumen-apposing metal stent through the duodenal stent.

drainage of purulent bile was observed ( $\triangleright$ Video 1) ( $\triangleright$ Fig. 4 , - Fig.5) and no complications occurred during the procedure and 6 months after.

Endoscopic ultrasound guided biliary drainage (EUS-BD) has been increasingly used as an alternative to percutaneous transhepatic biliary drainage after failed ERCP $[2,3]$. EUS-CD and EUS-HGS have been reported to have similar efficacity [4]. It seems that this new device decreases the morbidity of EUS-CD [5].

\section{Conclusion}

This is the first reported case of EUS-CD through a duodenal metal stent. Failed ERCP after duodenal stent placement is a frequent situation faced by endoscopists during the progression of advanced pancreatic cancer, and ERCP can be easily done using this method. 


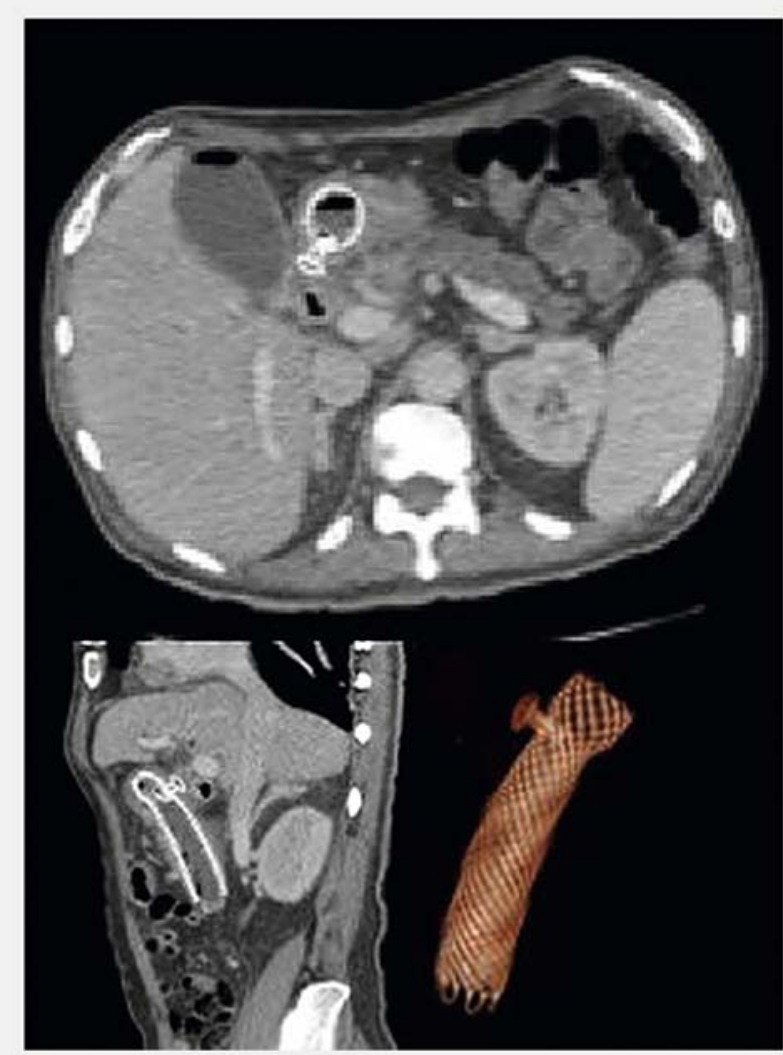

- Fig. 5 Computed tomography scan showing lumen-apposing metal stent through the duodenal stent.

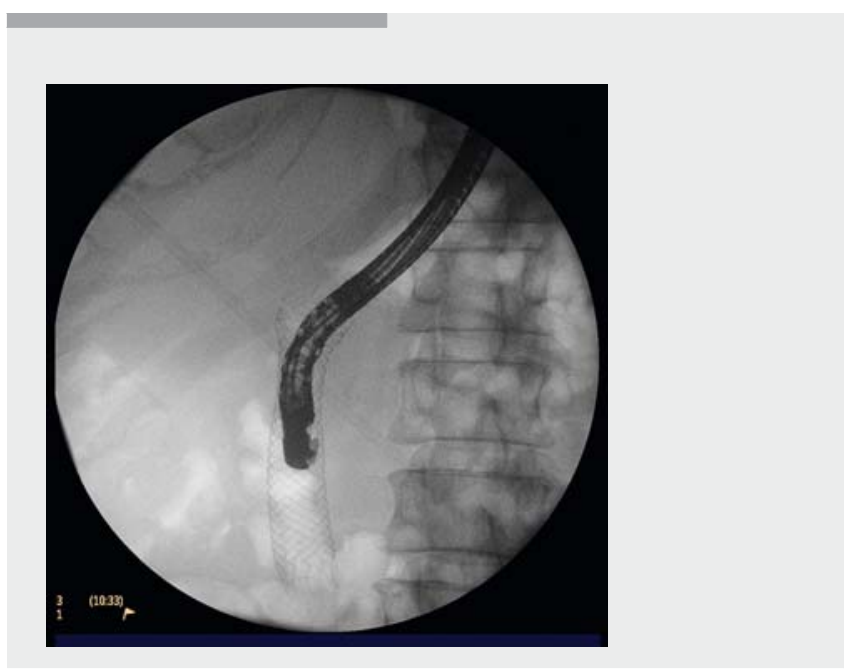

$\triangle$ Video 1 Endoscopic ultrasound-guided choledochoduodenostomy with a lumen-apposing metal stent through an uncovered metal duodenal stent
None

\section{References}

[1] Khashab MA, Valeshabad AK, Leung W et al. Multicenter experience with performance of ERCP in patients with an indwelling duodenal stent. Endoscopy 2014; 46: $252-255$

[2] Sharaiha RZ, Khan MA, Kamal F et al. Efficacy and safety of EUS-guided biliary drainage in comparison with percutaneous biliary drainage when ERCP fails: a systematic review and meta-analysis. Gastrointest Endosc 2017; 85: $904-914$

[3] Sportes A, Camus M, Greget M et al. Endoscopic ultrasound-guided hepaticogastrostomy versus percutaneous transhepatic drainage for malignant biliary obstruction after failed endoscopic retrograde cholangiopancreatography: a retrospective expertise-based study from two centers. Ther Adv Gastroenterol 2017; 10: 483-493

[4] Uemura RS, Khan MA, Otoch JP et al. EUS-guided choledochoduodenostomy versus hepaticogastrostomy: a systematic review and metaanalysis. J Clin Gastroenterol 2018; 52: $123-130$

[5] Kunda R, Pérez-Miranda M, Will U et al. EUS-guided choledochoduodenostomy for malignant distal biliary obstruction using a lumen-apposing fully covered metal stent after failed ERCP. Surg Endosc 2016; 30: $5002-5008$ 